Chirurgia (2019) 114: 18-28

No. 1, January - February

Copyright $@$ Celsius

http://dx.doi.org/10.21614/chirurgia.114.1.18

\title{
Mind the Gap Between Scientific Literature Recommendations and Effective Implementation. Is There Still a Role for Surgery in the Treatment of Locally Advanced Cervical Carcinoma?*
}

\author{
Alexandru Blidaru ${ }^{1,2}$, Cristian Bordea ${ }^{1,2}$, Traean Burcos ${ }^{2,3}$, Laura Dudus ${ }^{4}$, Dan Eniu ${ }^{5,7}$, Nicolae Ioanid ${ }^{6}$, \\ Gabriel Kacso ${ }^{7,8}$, Corina Minciuna ${ }^{4}$, Mircea Savu', Viorel Scripcariu ${ }^{6,9}$, Ștefan Tudor ${ }^{4}$, Cătălin Vasilescu ${ }^{2,4}$, \\ Silviu Voinea ${ }^{1,2}$ (Members of SURCECAN)
}

'Oncology Institute "Prof. Dr. Alexandru Trestioreanu", Bucharest, Romania

"University of Medicine and Pharmacy "Carol Davila", Bucharest, Romania

${ }^{3}$ General Surgery Discipline, Colțea Clinical Hospital, Bucharest, Romania

${ }^{4}$ Department of General Surgery, Fundeni Clinical Institute, Bucharest

${ }^{5}$ Oncology Institute "Prof. Dr. Ion Chiricuță", Cluj-Napoca, Romania

${ }^{6}$ Regional Institute of Oncology, Iași, Romania

'University of Medicine and Pharmacy "Iuliu Hațieganu", Cluj-Napoca, Romania

${ }^{8}$ RTC Amethyst, Cluj-Napoca, Romania

"University of Medicine and Pharmacy "Grigore T. Popa" Iași, Romania

\author{
Corresponding author: \\ Laura Dudus, MD \\ Fundeni Clinical Institute \\ 258 Fundeni Street, Bucharest, Romania \\ E-mail: lauracostin@gmail.com \\ Professor Catalin Vasilescu \\ Fundeni Clinical Institute, \\ 258 Fundeni Street, Bucharest, Romania \\ E-mail: catvasilescu@gmail.com \\ *This paper was partially presented \\ on March 22nd, 2018 in the public \\ session of Romanian Surgical Society, \\ branch Bucharest.
}

Abbreviations:

AGO - Gynecological Oncology Working Group;

CRT - chemoradiotherapy;

CT - computed tomography.

Received: 05.12.2018

Accepted: 25.01.2019

\section{Rezumat}

Mai există vreun loc pentru chirurgie în tratamentul cancerului de col uterin local avansat? De la recomandările ghidurilor terapeutice la practica clinică

Cele mai multe centre oncologice din lume recomandă actualmente în cancerul de col uterin avansat loco-regional (LACC) chimioradioterapie (fără chirurgie). În România, în practica clinică, un număr însemnat de paciente cu LACC sunt încă îndrumate către serviciile de chirurgie. Un grup de experți în oncologie şi chirurgie oncologică (grupul de studiu SURCECAN - surgery of cervical cancer) din România şi-au propus să analizeze cauzele acestei opțiuni. Au constat că nici indicațiile terapeutice din literatura de specialitate nu sunt consensuale. Condițile practice de realizare a radioterapiei (inclusiv brahiterapie) prezintă în România unele particularități: accesibilitate limitată la centrele specializate, dispoziție geografică neuniformă, etc. Pe de altă parte, şi statisticile din România şi cele internaționale arată prezența de țesut tumoral restant după iradiere. In aceste condiții, se poate spune că, în cazuri selectate, chirurgia păstrează încă un rol în tratamentul LACC. Este de dorit ca criteriile de indicație operatorie şi de abord 
DGGG - German Society for Gynecology and Obstetrics;

DKG - German Cancer Society;

EU - European Union;

EFRT - extended field radiotheraphy;

Gy - gray (unit);

RH - radical hysterectomy;

IMRT - Intensity-modulated radiation ther-

apy;

I0 - oncology institute;

IOB - Bucharest Oncology Institute;

IOR - Radiology - Oncology Institute;

LA - aortic lymphadenectomy;

LACC - locally advanced cervical cancer;

MRI - Magnetic Resonance Imagery;

OS - overall survival;

PET-CT - Positron emission tomography

- computed tomography;

RT - radiotherapy:

SURCECAN - Surgery of Cervical Cancer;

Surgery Coltea - General Surgery

Discipline, Colțea Clinical Hospital,

Bucharest;

Surgery Fundeni - Department of General

Surgery, Fundei Clinical Institute,

Bucharest. minim invaziv (laparoscopic, robotic) să fie precizate în urma unor studii efectuate la scară națională.

Cuvinte cheie: cancer de col uterin, chirurgie, plan terapeutic, ghiduri, chirurgie minim-invazivă, laparoscopie, chirurgie robotică

\begin{abstract}
According to evidence accumulated in the last years, many cancer centers recommend a treatment plan based solely on chemo-radiotherapy and exclude surgery from the treatment options in locally advanced cervical cancer (LACC). In Romania, surgery was at the forefront of therapeutic options. Nevertheless, current data shows that in fact, a large number of patients are still referred to surgery in various stages of diagnosis and treatment. It was noted that recommendations may differ, in spite of the wide dissemination of the literature data.Works published so far, discussing the role of surgery in LACC treatment shows a lack of consensus. A group of experts in oncology (SURCECAN research group - Surgery of Cervical Cancer) met for a session of the Romanian Surgical Society (Bucharest) on April 18, 2018. They found that LACC therapeutic strategy in Romania may differ somewhat from the European recommendations. On top of that, late enrolement to RT and low acces to specialized centers are the problem. Performing surgery not only allows the evaluation of the pathological response to chemo-radiotherapy, but also achieves a better local control. In conclusion, there is still a place for surgery within locally advanced cervical cancer treatment options. More trials need to be carried out in order to confirm the findings and establish high levels of confidence for each piece of information provided.
\end{abstract}

Key words: cervical cancer, surgery, therapeutic plan, guidelines, minimally invasive surgery, laparoscopy, robotic surgery

\section{Introduction}

Until recently, surgery has been the cornerstone of advanced cervical cancer treatment. However, in the last decade, radiotherapy (RT) and chemoradiotherapy (CRT) have made significant progress, have constantly improved the long term survival and decreased the recurrence rates. In accordance, surgical procedures performed in specialized centers by experienced surgical teams have also had better results. Despite that, surgical morbidity and mortality, though declining, could not be completely eliminated.

According to evidence accumulated in the last years, many cancer centers recommend a treatment plan based solely on CRT and exclude surgery from the treatment options. In Romania surgery was, traditionally, at the forefront of therapeutic options. However, a constant improvement was also noticed in the results of CRT in locally advanced cervical cancer (LACC). Nevertheless, current data shows that in fact, a large number of patients are still referred to 
surgery in various stages of diagnosis and treatment. Obviously, identifying the place of surgery in the treatment of locally advanced cervical cancer is of outmost interest for both surgeon and radiotherapist, in their efforts to provide the best chances of cure for patients with such a serious disease. It should be noticed that both in our experience and the data published in the international literature, up to $30-40 \%$ of LACC surgical patients following CRT are diagnosed with residual tumor tissue in the pathology examination of the hysterectomy specimen.

\section{Method}

A group of experts in Oncology met for a session of the Romanian Surgical Society (Bucharest) on April 18, 2018. Here they discussed the contemporary approach of LACC treatment and the level of implementation of the most used guidelines in current day practice. It was noted that in spite of the wide dissemination of the literature data, recommendations may differ. The SURCECAN (Surgery of Cervical Cancer) research group was founded in order to evaluate the gap between these standards and their utilization in the surgical practice of Romania.

The authors intended to:

1. Review the literature data in search of an agreement, posibily a consensus on the treatment of LACC.

This paper conveys the options of the authors and their personal choices regarding the literature data.

The present study has not been designed as a metaanalysis or systematic review. The main goal was not to make a formal, quantitative assessment of the results of previously published studies nor to present the data of any personal clinical series. The SURCECAN group purposefully limited the review to the most widely adopted guidelines and recommendations.

2. Answer a questionnaire about clinical practice in six major oncological centers in Romania.

\section{Terminology, Clasification}

According to FIGO classification, all cancers staged IB2 to IVA are included in LACC category. The advantages and disadvantages of different classifications such as TNM or FIGO are not the topic of our study and they will not be discussed in this paper. All participants have previously agreed on this subject.

\section{Results}

\section{Literature survey}

\section{National Cancer Institute (1)}

Surgery is recommended for stages IIB-IVAradical hysterectomy following neoadjuvant chemotherapy. This therapeutic scheme is not currently in clinical practice; further study is needed.

Chemoradiotherapy is the primary treatment for stage IB2 tumors of the cervix, which are larger than $4 \mathrm{~cm}$. For stages IIB, III and IVA the treatment options include CRT as well as intracavitary brachytherapy and neoadjuvant chemotherapy, prior to curative intent surgical resection. Although this neoadjuvant chemo-therapy approach is not currently included in clinical practice, there are several ongoing third phase studies researching its benefits.

\section{The National Comprehensive Cancer Network (2)}

Surgery is recommended for:

- stages IB2-IIA in patients with anatomy or extension of the disease that allows adequate irradiation;

- radical hysterectomy following neoadjuvant chemoradiotherapy

- or in most patients with stage IB2 and selected patients with stage IIA without mentioning of the selection criteria;

- radical hysterectomy with pelvic lymphadenectomy with/ without para-aortic lympha-denectomy.

Para-aortic lymphadenectomy for diagnostic purposes is indicated in stages IIB-IVA.

Stages IB2 and IIA2 are to be treated with 
concurrent Cisplatin based chemoradiation therapy - curative intent external radiation beam and brachytherapy. This is first level of reference information. Surgery is also an option for the majority of stage IB2 and selected cases of IIA patients (the selection criteria is not mentioned). The proposed procedure is type $\mathrm{C}$ hysterectomy with pelvic lymphadenectomy and para-aortic sampling, followed by adjuvant therapy. An approach to be considered for patients with limited invasion and favorable uterus anatomy for brachytherapy is concurrent Cisplatin based chemoradiotherapy, followed by hysterectomy and watchfull waiting. Nonetheless, if surgery as a primary treatment can not achieve R0, other treatment options available for stages IIB, III and IVA can be used.

Accurate imaging tests and/or surgical assesment of lymphnodes is crucial for stages higher than IA1 but especially for IIB-IV. Choosing the right treatment should take into consideration administrative issues, patient consent and other surgical limitations. Therefore, if radiological scans- CT, MRI or PET-CT- reveal absence of positive lymphnodes concurrent Cisplatin based chemotherapy and external radiation therapy plus brachytherapy is the treatment of choice. On the other hand, if positive lymphnodes are detected fine needle aspiration can be performed in order to confirm metastatic spread. Para-aortic lymphnode involvement implies either extended field RT or laparoscopic lymphadenectomy. MRI or CT should be performed post-operatively to check for residual tumor tissue. If both pelvic and para-aortic lymphnodes are involved, confirmation can be achived through extraperitoneal or laparoscopic lymphadenectomy.

\section{The European Society of Gynaecological}

Oncology/European Society for Radiotherapy and Oncology/European Society of Pathology Guidelines for the Management of Patients with Cervical Cancer (3)

\footnotetext{
Surgery is recommended for:

- stages IB2-IIA2 in selected patients performed procedure is radical hys-
}

terectomy and pelvic lymphnode sampling. If pelvic lymphnodes are positive, surgery is no longer indicated. Also, for stage IVA, pelvic exenteration is recommended.

Stages IB2-IIA2 might benefit from performing surgery - radical hysterectomy as an alternative to chemoradiotherapy. This is an option for patients with negative lymphnodes according to imaging tests and no additional risk factors such as: large tumor, lympho-vascular invasion (LVI) and/or stromal invasion. Assessing lymphnode spread during surgery is the first step. If micro and/or macro lymphatic metastases are detected, continuing surgery is unadvisable and patients should be evaluated and addressed to oncological treatment. Combining surgery and radiotherapy should at all costs be avoided, because associating radical interventions with postoperatory RT brings no additional benefit and increases morbidity rates.

If positive lymphnodes are suspected, then the choice of treatment is curative intent chemoradiotherapy. Para-aortic lymphnodes can either be resected or extended field radiation can be used.

Stages IIB, III and IVA are treated with CRT, with a special note for stage IVA where surgery- pelvic exenteration is feasible.

\section{Quick Reference for Healthcare Providers (Medical development divison, Ministry of Health (4)}

Surgery is not indicated in locally advanced cervical cancer.

Chemoradiotherapy is the recommended treatment in locally advanced cervical cancers.

\section{ESMO Guidelines (5)}

\section{Surgery is recommended for:}

- stage IB2-IIA - radical hysterectomy with pelvic lymphadenectomy, in selected patients, with/without para-aortic lympha denectomy;

- stages IIB-III: para-aortic lymphadenectomy for diagnostic purposes or radical 
hysterectomy with lymphadenectomy after neoadjuvant chemotherapy, alternative still under study;

- stage IVA: pelvic exenteration.

For almost two decades now, standard treatment for advanced cervical cancer stages IB2-IVA has been represented by chemoradiotherapy. Stages IB2-IIA benefit from CRT as well as surgical intervention - radical histerectomy with pelvic lymphodissection, to which para-aortic lymphodissection and sentinel ganglion mapping can be associated depending on the clinical presentation. Surgery is being considered for patients in need of adjuvant therapy, that have no additional risk factors - positive lymphnodes, parametrial invasion and high probability of a R1/R2 resection. Multi-modal treatment doesn't improve overall survival (OS) and increases toxicity.

Stages IIB-III are treated by CRT; the adjustment for the RT field requires PET-CT or para-aortic lymphodissection. A new approach suggests performing neoadjuvant chemotherapy followed by either surgery or radiotherapy. Two phase III clinical trials EORTC Protocol 55994 and NCT00193739are currently in progress but the results have not yet been published.

Stage IVA treatment includes either CRT or surgical intervention- pelvic exenteration.

\section{Korea Guidelines (6)}

Surgery is recommended for

- stages IB2-IIA2:

a. neoadjuvant chemoradiotherapy followed, depending on the clinical situation, by hysterectomy;

b. radical hysterectomy followed by adjuvant treatment;

c. neoadjuvant chemotherapy followed by radical hysterectomy, currently under study;

- stage IIB-IVA, laparoscopic or extraperitoneal para-aortic lymphadenectomy.

Stages IB2-IIA2 are treated according to a concurrent Cisplatin based chemoradiotherapy scheme. Depending on the clinical presentation of the patient, adjuvant hysterectomy can be subsequently carried out. Another option is performing radical hysterectomy upfront, followed by tailored adjuvant treatment. Both approaches have similar overall survival rates. A retrospective study of patient data shows that for this subgroup, neoadjuvant chemotherapy is a feasible option. Five year-overall survival rates are similar to other treatment schemes which include radiotherapy or surgical intervention as a sole approach. Nonetheless, neoadjuvant chemotherapy is still debatable and will be established by the time EORTC phase III randomized study will end.

Evaluating para-aortic lymphnode involvement is crucial for patients staged IIB-IVA. Extraperitoneal or laparoscopic lymphadenectomy is the most accurate method to determine the best treatment approach. If para-aortic lymphnodes are negative Cisplatin based CRT is performed. Otherwise, extended field RT is necessary. CRT treatment scheme should be tailored according to patient clinical presentation.

\section{A change of paradigm in the treatment of cervical cancer (7)}

Surgery is not indicated in patients with associated histopathological risk factors.

Management of the locally advanced cervical cancer patients has been controversial for decades. The US utilizes chemoradiotherapy as the treatment of choice for stages IB2-IVA tumors, while in Europe, surgery is preferred for cases which have additional negative risk factors - either clinical or histopathological when CRT is usually considered as an adjuvant method. In 2014, AGO along with two other German committees - the German Society for Gynecology and Obstetrics (DGGG) and the German Cancer Society (DKG) have revised the S2k Guide of diagnosis and treatment, taking into consideration the feedback received after publishing. The new S3 Guide registers a "shift of paradigm"recommending the unimodal treatment. Therefore, patients presented with negative prognostic factors such as poor differentiation (G3), lymphovascular invasion (L1, V1) or 
large tumors are proposed for CRT instead of a surgical intervention.

\section{Surgical Resection after concurrent} chemoradiotherapy for locally advanced cervical carcinoma (8)

This study shows that surgery achieves superior local control of the disease. The overall survival is increased in comparison to the control group, but without analyzing the data on associated morbidity.

Although local recurrence rates are low, the exact effects of this multimodal approach on morbidity are not well known. The OS is statistically higher in the work group but one emerging problem is the selection process which is crucial. Another major issue is the ability to make a differential diagnosis between postradiation fibrotic tissue and residual tumor tissue.

\section{Extrafascial hysterectomy after concurrent} chemoradiotherapy in locally advanced cervical adenocarcinoma (9)

Adjuvant extrafascial hysterectomy following neoadjuvant chemoradiotherapy improves overall survival.

Performing total hysterectomy with bilateral salpingo-oophorectomy following chemo-radiotherapy in patients with locally advanced cervical cancer has shown a significant improvement of overall survival and disease free survival. Pathology reports found that $41.1 \%$ of patients had microscopic residual tumor tissue, while 5.8\%- macros-copic tumor. Multiple risk factors were evaluated - clinical stage, differentiation grade, tumor volume, number of chemotherapy cycles performed before and during radiation. Tumor volume proved to be the most relevant, though without statistical significance. Further trials need validation in choosing the right candidates and the optimal treatment of choice.

Principles and practices gynecologic oncology (10)

Surgery is not recommended for locally advanced cervical cancer.

Adjuvant extrafascial histerectomy following $\mathrm{RT}$ was the preffered treatment option for stage IB2 cervical cancer. Later studies have shown that this approach does not improve OS compared to RT alone, not to mention the high incidence of adverse effects that this type of multimodal therapy has been associated with. Therefore, the standard treatment for stages IB2-IVA is chemoradiotherapy.

\section{Clinical practice guidelines GYNE-004 version 6 (11)}

Surgery is recommended for stages IB2-IIA: radical hysterectomy and pelvic lymphadenectomy with/without paraortic lymphadenectomy (specific selection criteria not mentioned).

Perpetuates the idea that surgery- radical histerectomy and pelvic lymphadenectomy with/without para-aortic lymphadenectomy - is a feasible alternative to CRT for stage IB2 patients. Nonetheless the selection criteria in choosing the right treatment option is unspecified.

For stages IIA1 and IIA2, surgical intervention is also to be considered in selected cases, but no additional information is provided.

Medically fit patients, staged IIB,III or IVA are submitted to CRT, while RT alone, palliative or with curative intent is reserved to unsuitable ones.

\section{Radiochemotherapy versus Radiochemotherapy \\ plus Surgery in Stage IIB Cervical Cancer: A phase III Single Institution randomized trial (12)}

The conclusion of this study is that surgery does not influence overall survival and disease free survival rates; Chemoradiotherapy is still the standard treatment for with stage IIB patients.

This study evaluates the importance of performing surgery - a radical hysterectomy as a sequence in the multimodal approach of stage IIB cervical cancer patients. Two randomized groups were selected as follows: A - patients treated with adjuvant surgery; 
B - patients treated with CRT exclusively. Although group B registered a higher local recurrence rate and group A a higher distant metastases occurrence, there is virtually no difference between them. The results suggest that surgical intervention brings no benefit to the overall survival and disease free survival and that CRT is the standard treatment.

Results of the GYNECO 02 Study an FNCLCC Phase III Trial Comparing Hysterectomy with no hysterectomy in patients with a (Clinical and Radiological) complete response after chemoradiation therapy for stage IB2 or II Cervical Cancer (13)

This study shows that overall survival and disease free survival are not influenced by the addition of surgery to the therapeutic scheme.

The role of extrafascial hysterectomy after CRT is evaluated in this study. Enrollment criteria included patients with complete response after CRT - mostly stages IB2 and II - patients with macroscopic residual tumor tissue being automatically assigned for surgery. Patient selection was difficult owing to the fact that surgeons are reluctant in changing their current care practices. As a result, the rendered data base was insufficient for statistical analysis, but a few important discoveries were made. One third of the patients with resection had residual tumor tissue in the histopathological examination report, including a number of cases with remnant tumor larger than $1 \mathrm{~cm}$. This only emphasizes the limits of the imaging methods. Following surgery, local recurrence rates were low but regional recurrences, arising from the lymphatic space were higher. This is where PET-CT or laparoscopic staging lymphadenectomy before CRT would improves results. A rise in the morbidity rates was observed when performing radical hysterectomy, which appears to be unnecessary unless the tumor is locally invasive or bulky.

The study concludes that overall and disease-free survival are not influenced by the adjuvant surgical intervention, although the statistical power is low. Therefore, hysterectomy remains optional.

\section{Japanese Guidelines (14)}

Surgery is recommended for stages IB2-IIA2radical hysterectomy associated or not with adjuvant chemotherapy.

Stages IB2 and II treatment options include chemoradiotherapy or radical histerectomy, followed or not by adjuvant therapy. Adjuvant chemotherapy is being considered, depending on tumor dimensions and invasion. To determine radiation field or appreciate lymphatic spread, para-aortic lymphodissection is required, unless radiologic imaging is not accurate.

Nonetheless, CRT is the treatment of choice for stages III and IVA cervical cancer. Surgery is not recommended, regardless of the histological type.

\section{Monitorul Oficial nr 608 bis (15)}

Surgery is recommended for stages IB2-IIBradical hysterectomy with pelvic lymphadenectomy following neoadjuvant chemo-radiotherapy. Radical hysterectomy is also recommended after neoadjuvant chemo-radiotherapy if residual tumor tissue is present and the parameters are not involved.

Standard treatment for stage IB2 patients is chemo-radiotherapy- 56 Gy, 46 Gy external beam radiation and 10 Gy brachytherapy, followed by re-evaluation of each case. A decision is then made whether to assign patients to radiation therapy alone or to surgery- a radical hysterectomy with pelvic lymphadenectomy (no mention of the selection criteria). During the intervention, if paraaortic lymphnodes appear to be invaded, either resectable or not, extended field RTis recommended in addition to chemotherapy. For patients with positive pelvic lymphnodes on the pathology report, extended field radiotheraphy (EFRT) can be performed prophylactic in association with Cisplatin based chemotherapy.

Stage IIA benefits of the same treatment approach, with a special note to EFRT. If imaging shows enlarged para-aortic lymphnodes, then extended field chemoradiotherapy can be performed upfront.

For stage IIB patients the standard of care 
is CRT, although selected cases can be referred to surgery, after careful evaluation (no mention of the selection criteria). Upon completion of radiation therapy the response is evaluated. If no parametrial invasion is detected, but residual central tumor is found, surgical intervention is recommended- radical hysterocolpectomy.

CRT is the treatment of choice for stage IVA.

\section{Scottish Guidelines - SIGN (16)}

Surgery is not indicated in locally advanced cervical cancer.

Locally advanced cancer of the cervix is generally treated by chemoradiotherapy, while surgical intervention is to be avoided in this group of patients owing to the high risk of positive margins and lymphnode involvement.

\section{Anderson (17)}

\section{Surgery is only indicated in stage IVA (pelvic exenteration).}

Locally advanced cervical cancer treatment is radiotherapy with concurrent chemotherapycisplatin alone or with 5-fluorouracil. Patients that do not tolerate well cisplatin receive only $\mathrm{RT}$. If imaging evaluation reveals positive para-aortic lymphnodes extended field radiation therapy is recommended.

Stage IVA managements is particularly difficult because the tumor is generally fixed to pelvic structures and associated with regional metastatic desease. Intracavitary $\mathrm{RT}$ is frequently hard to use, because of the vesico-vaginal fistula that might occur before or during treatment. If the fistula is small or absent, brachytherapy must be performed. An alternative to this procedure is IMRT or external beam radiation followed by anterior/total pelvic exenteration. However, approximately $10-20 \%$ of stage IVA tumors are curable by RT alone. Although few studies have evaluated the role of concurrent chemotherapy, it is undoubtedly included in this stage treament scheme.

Answers to the questionnaire are mentioned in Table 1 and Table 2.

\section{Discussions}

Surgical oncolgy is a constantly evolving discipline. Standards, recommendations and guidelines are modified periodically in light of new research. Moreover, literature published so far, discussing the role of surgery in LACC treatment shows a lack of consensus. The reconciliation between medical literature data and current day practice in our country represents an objective of great interest and would be a way to achieve better oncological results.

1. Recent literature brings forward many arguments that support the LACC's definitive CRT (or more precisely "curative intent"). Nonetheless, a review of the guidelines and studies published so far, discussing the role of surgery in LACC treatment shows a lack of consensus. In fact, answers given by the study participants reveal that a large number of patients with LACC are still referred to surgical treatment. Therapeutic guidelines (bibliographic sources) and recent systematic analyses (18) assign surgery different roles in management algorithms. These guidelines may vary somewhat in

Table 1. Questionnaire on current surgical practice in the treatment of locally advanced cervical cancer

1. Recommendation for surgical treatment in locally advanced cervical cancer (IB2 - IVA)

a. preferably, after CRT

b. in selected cases after CRT. What are the selection criteria?

c. never, I opt for definitive CRT

2. Surgical technique option

a. Simple hysterectomy

b. Simple hysterectomy + ganglion sampling

c. Radical hysterectomy ( $\mathrm{RH}$ ) (some details of the technique)

d. $\mathrm{RH}+$ pelvic lymphadenectomy

e. $\mathrm{RH}+$ pelvic lymphadenectomy + lombo-aortic lymphadenectomy

f. other options (technical details)

3. If surgery is the option, for what reason?

a. There is residual tumor tissue in a large number of cases after CRT

b. Radiotherapy in Romania does not have the same level of performance as the one in North America or Western Europe

c. Other explanations 
Table 2. The SURCECAN members answers and recommendations

\begin{tabular}{|c|c|c|c|}
\hline \multicolumn{2}{|c|}{ 1. IOB - Surgery } & $a, b$ & $\begin{array}{l}\text { The selection criteria: completion of CRT with macroscopic residual tumor } \\
\text { amenable to surgery. }\end{array}$ \\
\hline & IOB - RT & a & $\begin{array}{l}\text { For stage I B2 patients following neoadjuvant treatment and tumor downsizing } \\
\text { therefore enabling surgical approach. }\end{array}$ \\
\hline & IO - CLUJ & b & $\begin{array}{l}\text { If residual tumor tissue is detected and surgical intervention is technically } \\
\text { possible }\end{array}$ \\
\hline & IOR lasi & b & $\begin{array}{l}\text { Selection criteria for stage I B2 - IV A patients: complete or quasi-complete } \\
\text { response (clinical and/or imagistic) and absence of local invasion - vagina, } \\
\text { parameters. }\end{array}$ \\
\hline & Surgery - Coltea & a & \\
\hline & Surgery - Fundeni & a & \\
\hline \multirow[t]{6}{*}{2.} & IOB - Surgery & f & Totally extended lymphadenohysterocolpectomy IOB technique \\
\hline & IOB - RT & $\mathrm{b}$ & $\begin{array}{l}\text { Limited surgical intervention due to additional risk of complications. Simple } \\
\text { hysterectomy }+/ \text { - lymphnode sampling. }\end{array}$ \\
\hline & 10 - CLUJ & e & $\begin{array}{l}\text { RH + pelvic lymphadenectomy + lombo-aortic lymphadenectomy } \\
\text { (actually LA biopsy) }\end{array}$ \\
\hline & IOR lasi & d,e & \\
\hline & Surgery - Coltea & d & \\
\hline & Surgery - Fundeni & d & Laparoscopy, Robotic surgery \\
\hline & IOB - Surgery & $a, b$ & \\
\hline & $\mathrm{IOB}-\mathrm{RT}$ & a & \\
\hline & $10-$ CLUJ & a & \\
\hline & IOR lasi & $a, b$ & \\
\hline & Surgery - Coltea & a & \\
\hline & Surgery - Fundeni & a & \\
\hline
\end{tabular}

content and have different approaches. Their recommendations of surgery, chemotherapy and radiotherapy in various treatment plans, with heterogeneous indications and results may vary as well. And not only medical traditions, but also treatment conditions, especially those of radiotherapy, are different from one country to another. Locally advanced cervical cancer therapeutic strategy in Romania may differ somewhat from the European recommendations (ESGO and ESTRO 2018). The RT scheme includes external beam radiation - $50 \mathrm{~Gy}$ and brachytherapy - 15 Gy along with CHT to boost performance. Radiotherapy in curative doses is not routinely performed probably because of the associated risks of patients developing complications (vesico-vaginal or recto-vaginal fistulas, radiation enteritis, extensive fibrosis).

2. Other issues that should be mentioned are should be mentioned are poor screening (19), late enrollment to RT and low acces to specialized centers. Despite recent investments, there is currently about 1.5 linear accelerators per million inhabitants compared to an average of 5.5 in the EU. Also, the geographical access to radiation therapy facilities is inappropriate. They are mostly concentrated in oncology institutes, large cities and university centers. Another major issue is the access to brachy-therapy, which is mandatory for curative treatment. Therefore, radiotherapy in Romania may often be considered suboptimal.

3. It should be noticed that both in our experience and the data published in the international literature, up to $30-40 \%$ of LACC surgical patients following CRT are diagnosed with residual tumor tissue in the pathology examination of the hysterectomy specimen (20). There is the opinion that, paradoxically, about $60 \%$ of these women with microscopic residual tumor do not develop recurrences. Other teams, however, propose "salvage" hysterectomy if there is 
imaging data showing residual tumor after the definitive CRT (20). Performing surgery not only allows evaluating the pathological response to CRT, but also achieves a better local control.

4. Clinical and imaging data may play an important role in evaluating local and regional extent of the disease after completing CRT. But such tests have their own limitations. Postradiation tissue can not always be differentiated from residual tumor tissue, therefore many patients may be in fact misdiagnosed. Consequently, surgical exploration is still a valuable method to establish whether the patient is eligible to receive further treatment or not. As we said, the extent of the surgery can variate from exploratory laparoscopy to radical hysterectomy, pelvic ilio-obturator lymphnode dissection, para-aortic lymph node sampling and even complex resections involving other affected organs.

In addition, a special note must be made for stage IVA cervical cancer (either bladder and/or rectal involvement). It is a consensus view of the literature studied that surgery (pelvic exenteration) is the recommended treatment.

It has to be said that there is a dynamic and continuous process in surgical practice including technical innovations in instruments used (laparoscopy, robotics, NOTES), as well as new concepts and perspectives recently applied to the LACC surgery [the surgery of morphogenetic fields (21-23)]. Minimally invasive surgery continues to play an important role in gynecological oncology as an alternative to open surgery (24). However, the long-term effectiveness of these methods still need to be confirmed by future studies.

\section{Conclusion}

Taken together, we can conclude that there is still a place for surgery within LACC treatment options. Considering some precautionary measures and setting proper indications for each case, it can be said that surgical treatment is not yet to be excluded. More trials need to be carried out in order to confirm the findings and establish high levels of confidence for each piece of information provided. Meanwhile, multidisciplinary discussion of all LACC patients, properly staged (including FDG-PETCT or staging lymphadenectomy if decided), and concurrent chemo-radiation (CRT) and modern brachytherapy (including interstitial if needed) shall be proposed- if available- for most if not all cases accepting this strategy risk and benefits. If good quality CRT cannot start in due time, some cases might be better served by surgery. Careful clinical and imaging follow-up is mandatory for keeping the opportunity of a salvage radical surgery.

\section{Author's Contributions}

Authors share equal contributions and are listed in alphabetical order.

\section{Aknowledgements}

Special thanks to other participants who provided useful information on the topic.

\section{Conflict of Interest}

The authors declare no conflicts of interests.

\section{References}

1. Cervical Cancer Treatment $(P D Q(R))$ : Health Professional Version. PDQ Cancer Information Summaries. Bethesda (MD)2002.

2. Koh W, GreeR BE, Abu-Rustum NR, Campos SM, Cho KR, Chon HS, et al. NCCN Clinical Practice Guidelines in Oncology: Cervical Cancer. 2018 [12.11.2018]; Available from: www.nccn.org/professionals/physician_gls/pdf/cervical.pdf.

3. Cibula D, Potter R, Planchamp F, Avall-Lundqvist E, Fischerova D, Haie Meder C, et al. The European Society of Gynaecological Oncology/European Society for Radiotherapy and Oncology/European Society of Pathology Guidelines for the Management of Patients With Cervical Cancer. Int J Gynecol Cancer. 2018;28(4):641-55.

4. Medical Development Division MoHM. Quick reference for healthcare providers:Management of cervical cancer. 2 ed. www.moh.gov.my2017.

5. Marth C, Landoni F, Mahner S, McCormack M, Gonzalez-Martin A, Colombo N, et al. Cervical cancer: ESMO Clinical Practice Guidelines for diagnosis, treatment and follow-up. Ann Oncol. 2017;28(suppl_4):iv72-iv83.

6. Lim MC, Lee M, Shim SH, Nam EJ, Lee JY, Kim HJ, et al. Practice guidelines for management of cervical cancer in Korea: a Korean Society of Gynecologic Oncology Consensus Statement. J Gynecol Oncol. 2017;28(3):e22.

7. Mallmann P. A Change of Paradigm in the Treatment of Cervical 
Cancer. Oncol Res Treat. 2016;39(9):500

8. Maghous A, Elmarjany M, Mamouche E, Andaloussi K, Bazine A, al. e. Surgical Resection after Concurrent Chemoradiotherapy for Locally Advanced Cervical Carcinoma. J Oncol Med \& Pract. 2016;1(2):107.

9. Yang J, Shen K, Wang J, Yang J, Cao D. Extrafascial hysterectomy after concurrent chemoradiotherapy in locally advanced cervical adenocarcinoma. J Gynecol Oncol. 2016;27(4):e40.

10. Levine D, Dizon D, Yashar C, Barakat R, Berchuck A, Markman M, et al. Handbook for principles and practice of gynecologic oncology. 2 ed2015. p. 598-619.

11. Services AH. Clinical Practice Guidelines GYNE-004 Version 6. Cancer of the uterine cervix. 2015 [22/10/2015]; Available from: https://www.albertahealthservices.ca/assets/info/hp/cancer/if-hpcancer-guide-gyne004-cervical.pdf.

12. Suteu P, Ordeanu C, Coza C, Rancea A, Traila A, Todor N, et al. Radiochemotherapy versus Radiochemotherapy plus surgery in stage IIB cervical cancer:A phase III single institution randomized trial. 2014;20(2):47-53.

13. Morice $P$, Rouanet $P$, Rey $A$, Romestaing $P$, Houvenaeghel G, Boulanger JC, et al. Results of the GYNECO 02 study, an FNCLCC phase III trial comparing hysterectomy with no hysterectomy in patients with a (clinical and radiological) complete response after chemoradiation therapy for stage IB2 or II cervical cancer. Oncologist. 2012;17(1):64-71.

14. Ebina $Y$, Yaegashi N, Katabuchi H, Nagase S, Udagawa Y, Hachisuga T, et al. Japan Society of Gynecologic Oncology guidelines 2011 for the treatment of uterine cervical cancer. Int J Clin Oncol. 2015;20(2):240-8.

15. Anghel R, Nagy V, Rancea A, Coza O, Kacso G, Aldea B, et al. Ghid de diagnostic si tratament al cancerului de col uterin MONITORUL
OFICIAL nr 608 bis din 3 septembrie 2009. 2009.

16. James RM, Cruickshank ME, Siddiqui N, Guideline Development G. Management of cervical cancer: summary of SIGN guidelines. BMJ. 2008:336(7634):41-3.

17. Eifel PJG, D.M.; Kavanagh, J.J.; Silva, E.G. MD Anderson Cancer Care Series: Gynecologic Cancer. New York: Springer-Verlag; 2006.

18. Nitipir C, Orlov, C., Popa, A. M., Slavu, I.,, Tulin A. Is adjuvant hysterectomy an option after radio-chemotherapy for locally advanced cervical cancer? A review. . Journal of Clinical and Investigative Surgery2018. p. 9-13

19. Păvăleanu I, Gafițanu D, Ioanid N, Grigore M. Preliminary results of the first cervical cancer screening programme in the North Eastern region of Romania. J Med Screen. 2018;25(3):162-165

20. Ota T, Takeshima N, Tabata T, Hasumi K, Takizawa K. Adjuvant hysterectomy for treatment of residual disease in patients with cervical cancer treated with radiation therapy. $\mathrm{Br} \mathrm{J}$ Cancer. 2008; 99(8):1216-20.

21. Vasilescu C, Stanciulea O, Popa M, Anghel R, Herlea V, Florescu A. Total laparoscopic radical hysterectomy with pelvic lymphadenectomy for endometrial cancer. Chirurgia (Bucur). 2008; 103(1):99-102.

22. Wolf B, Ganzer R, Stolzenburg JU, Hentschel B, Horn LC, Hockel M. Extended mesometrial resection (EMMR): Surgical approach to the treatment of locally advanced cervical cancer based on the theory of ontogenetic cancer fields. Gynecol Oncol. 2017;146(2):292-8.

23. Vasilescu C, Sgarbura O, Tudor S, Popa M, Turcanu A, Florescu A, et al. Robotic radical hysterectomy with pelvic lymphadenectomy: our early experience. Chirurgia (Bucur). 2009;104(4):393-7.

24. Vasilescu C, Tudor S, Popa M, Aldea B, Gluck G. Entirely robotic total pelvic exenteration. Surg Laparosc Endosc Percutan Tech. 2011;21(4):e200-2. 